\title{
Motivação partidária nas transferências voluntárias da União: o papel do Legislativo Federal
}

\author{
Fernanda L. Marciniuk ${ }^{1}$ \\ Maurício S. Bugarin ${ }^{2}$ \\ Débora C. Ferreira ${ }^{3}$
}

\section{Resumo}

Este artigo investiga a influência do alinhamento partidário entre atores políticos das esferas federal e municipal na determinação das transferências voluntárias federais aos municípios, com especial enfoque na identidade partidária entre deputados federais e prefeitos, a partir do indicador de Quociente Locacional de Bendavid-Val. A análise econométrica confirma o efeito positivo e significante dessa identidade partidária, indicando o importante papel desempenhado pelos deputados federais na distribuição partidária de transferências intergovernamentais. A principal contribuição deste trabalho é ir além do tradicional alinhamento entre prefeito e Presidente da República e investigar o papel dos parlamentares federais na distribuição partidárias das transferências voluntárias.

\section{Palavras-Chave}

Transferências voluntárias. Convênios públicos. Quociente Locacional de Bendavid-Val. Identificação partidária. Transferências partidárias do Legislativo.

\footnotetext{
Abstract

This paper presents empirical evidence that the distribution of federal voluntary transfers is biased in favor of municipalities in which the mayor's party has higher identification with the coalition of parties in the Legislature that has strong representation in the municipality. This research measures party identification between the federal Legislature and the municipal Executive branch based on Bendavid-Val's locational quotients applied to voting data. The paper's main contribution is to go beyond the mayor-president partisan transfers' approach, and to shed light on the important role the federal Legislature plays in the partisan distribution of subnational voluntary transfers.

1 Pós-doutoranda - Universidade de Brasília - Departamento de Economia - Campus Darcy Ribeiro Prédio da FACE - Asa Norte - CEP: 70910-900 - Brasília/DF - Brasil - E-mail: flmarciniuk@gmail.com ORCID: https://orcid.org/0000-0003-0999-3822.

2 Professor - Universidade de Brasília - Departamento de Economia - Campus Darcy Ribeiro Prédio da FACE - Asa Norte - CEP: 70910-900 - Brasília/DF - Brasil - E-mail:bugarin.mauricio@gmail.com URL: www.bugarinmauricio.com - ORCID: https://orcid.org/0000-0003-1177-7344.

3 Doutoranda - Universidade de Brasília - Departamento de Economia - Campus Darcy Ribeiro Prédio da FACE - Asa Norte - CEP: 70910-900 - Brasília/DF - Brasil E-mail: debora.costaferreira91@gmail.com - ORCID: https://orcid.org/0000-0003-2379-4790. Recebido: 30/01/2019. Aceite: 22/01/2020.

Editor Responsável: Rafael Terra de Menezes
}

(c) (i) (\$) Esta obra está licenciada com uma Licença Creative Commons Atribuição-Não Comercial 4.0 Internacional. 


\section{Keywords}

Voluntary intergovernmental transfers. Intergovernmental grants. Bendavid-Val's locational coefficient. Party identification. Legislative partisan transfers.

\section{JEL Classification}

H77. D72. C33.

\section{Introdução}

A literatura econômica tem identificado tanto teórica quanto empiricamente a influência do alinhamento partidário entre presidente e prefeito sobre o nível de transferências voluntárias recebidas do governo federal. Contudo, pouco se investigou acerca do impacto da identidade partidária entre Poder Legislativo federal e Executivo local no volume dessas transferências.

Apesar da importância do presidente na aprovação e liberação de recursos das emendas parlamentares à Lei Orçamentária Anual (LOA), os deputados federais participam de forma ativa da sua elaboração, desempenhando um importante papel na interligação entre o governo federal e os governos locais e, consequentemente, na determinação das políticas públicas subnacionais. Ademais, estudos do Legislativo brasileiro sugerem que a disciplina partidária na atividade parlamentar é capaz de conferir influência aos partidos no processo orçamentário (Mueller 2003; Pereira e Mueller 2002; Figueiredo e Limongi 2002, 2008; Nicolau 2006).

Nesse contexto, o presente artigo tem por objetivo principal investigar a influência do alinhamento partidário entre atores políticos das esferas federal e municipal na determinação do montante de transferências voluntárias federais destinadas aos municípios, com especial enfoque na identidade partidária entre deputados federais e prefeitos. Como objetivo secundário, busca testar as hipóteses teóricas de que as transferências voluntárias da União são direcionadas em maior medida para municípios cujos prefeitos pertencem ao partido do presidente e a partidos da base governista em âmbito federal.

1 Ferreira e Bugarin 2004, 2007, Brollo e Nannicini 2012, Sakurai e Theodoro 2020, Bugarin e Marciniuk 2017, para o Brasil; Wright 1974 (EUA); Ansolabehere e Snyder 2006 (EUA); Gonschorek et al. 2018 (Indonésia); Khemani 2003, 2007 (India); Kraemer 1997 (México); Porto e Sanguinetti 2001 (Argentina); Rozevitch e Weiss 1993 (Israel); Solé-Ollé e Sorribas-Navarro 2008 (Espanha); Tamura 2010 (Japão); Veiga e Pinho 2007 (Portugal). 
Para atingir esses objetivos, adotou-se como estratégia empírica o modelo de painel com efeitos fixos, utilizando a base de convênios públicos federais de 2001 a 2012 como proxies para as transferências voluntárias no período. Foram incorporadas como variáveis de interesse (i) a identidade partidária entre o prefeito e a zona de maior influência do partido do deputado federal, obtida com base no indicador de Quociente Locacional criado por Bendavid-Val (1991); a (ii) identidade partidária entre o presidente e o prefeito; bem como (iii) a identidade partidária entre o prefeito e a coalizão do partido do presidente. Incluíram-se ainda variáveis de controle referentes a características políticas, fiscais e sociodemográficas dos municípios e a atributos pessoais dos prefeitos, construídas por Marciniuk e Bugarin (2019).

Tendo como variável dependente a receita total recebida pelos municípios por meio de convênios, este artigo encontra evidência de que municípios que possuem identidade partidária entre o Poder Legislativo Federal e o Poder Executivo Municipal recebem transferências voluntárias superiores aos municípios que não possuem essa identidade (em média, um aumento de $\mathrm{R} \$ 3,24$ por habitante). Já o efeito da identidade partidária entre prefeito e presidente corresponde, em média, a $\mathrm{R} \$ 7,43$ a mais no valor total dos convênios por habitante, em linha com o que já havia sido evidenciado por Ferreira e Bugarin $(2004,2007)$ e outros estudos mais recentes.

Outros resultados obtidos pela análise são os de que prefeitos de primeiro mandato e candidatos à reeleição recebem maiores montantes de transferências voluntárias (em média, $\mathrm{R} \$ 8,03$ adicionais por habitante), ao passo que os prefeitos de primeiro mandato e que não são candidatos à reeleição recebem menos transferências voluntárias, corroborando intuições de Marciniuk e Bugarin (2019). Além disso, o estudo apresenta evidência de que partidos mais à esquerda receberam maiores volumes de transferências voluntárias, um resultado também encontrado em Bugarin e Marciniuk (2017) e que talvez reflita o fato de que um partido de esquerda ocupou a presidência do país na maior parte do período considerado, entre outros achados.

Os resultados aqui apresentados corroboram a hipótese teórica de que os partidos políticos desempenham importante papel no direcionamento das transferências voluntárias da União para os municípios, não somente por meio do alinhamento entre prefeitos e presidente, mas também pela identidade partidária entre prefeitos e deputados federais. No entanto, os 
resultados sugerem que o Executivo nacional ainda exerce papel prevalente sobre esse direcionamento no período de análise.

Este trabalho inova na literatura econômica ao avaliar empiricamente a relação entre a distribuição espacial dos votos para os partidos dos deputados da Câmara Federal e a sua relação com a distribuição de transferências voluntárias federais aos municípios. A principal inovação metodológica, além da utilização da base de convênios públicos federais como proxies para as transferências voluntárias, é o uso do Quociente Locacional de BendavidVal para medir a força do partido de um deputado em um determinado município.

Além desta introdução, o trabalho estrutura-se da seguinte forma: a Seção 2 apresenta uma contextualização institucional acerca da descentralização fiscal no Brasil e das transferências voluntárias. A seção 3 traz o referencial teórico sobre o papel dos partidos políticos na distribuição de recursos via transferências voluntárias. Em seguida, a seção 4 discute os resultados da análise empírica, com a apresentação do modelo e das variáveis utilizadas para os testes econométricos. Por fim, a seção 5 traz as conclusões desta pesquisa.

\section{Contextualização Institucional}

\subsection{Descentralização Fiscal no Brasil}

A descentralização fiscal introduzida pela Constituição Federal de 1988 e o consequente fortalecimento dos municípios foram responsáveis por profundas mudanças nas instituições dos governos locais, alterando os sistemas de decisões e as práticas dos atores políticos em todos os níveis de governo. Com ela, os municípios se tornaram responsáveis pela implantação de grande parte dos programas do governo federal e pela alocação de parte considerável dos recursos nacionais (Bugarin e Gadelha 2020). No entanto, apesar de o Brasil optar por um sistema fiscal descentralizado para a prestação de serviços públicos, adotou-se um sistema de arrecadação de tributos centralizado e com posterior redistribuição para os governos locais (Mendes et al. 2008). 
Assim, sob a lógica do federalismo brasileiro, as transferências de recursos entre os entes federativos se tornaram uma ferramenta de extrema importância para viabilizar o melhor desempenho dos entes governamentais. Fundamentadas em argumentos econômicos e políticos (Barbosa 1998; Bugarin et al. 2010), as transferências são consideradas essenciais para suprir a lacuna entre a capacidade e a necessidade de se proverem serviços públicos de modo uniforme para todos os cidadãos e, além disso, para resolver problemas de externalidades, tais como o efeito spillover. ${ }^{2}$

Apesar de sua importância, a partilha do "bolo tributário" via transferências pode gerar ineficiência na alocação dos recursos públicos. ${ }^{3}$ Portanto, um bom desenho do sistema de transferências de recursos governamentais é um elemento importante no contexto institucional brasileiro tanto para o equilíbrio fiscal quanto para a qualidade da intervenção do setor público na economia.

Grande parte do montante enviado aos entes subnacionais é distribuída sob a forma de transferências constitucionais ou legais - as denominadas transferências obrigatórias. As transferências constitucionais consistem na distribuição de recursos provenientes da arrecadação de tributos federais ou estaduais, aos estados, Distrito Federal e municípios, com base em dispositivos constitucionais como, por exemplo, os Fundos de Participação Estaduais ou Municipais. As transferências legais são reguladas por leis específicas e seus recursos são repassados para acorrer a despesas específicas. ${ }^{4}$ Bugarin e Mariciniuk (2017) apresentam evidências estatísticas de que essas transferências obrigatórias são técnicas e não são enviesadas por considerações de alinhamento político entre prefeito e presidente e/ ou governador.

2 Spillover ou "efeito transbordamento" reflete como o incremento do gasto de uma determinada unidade da federação influencia outra unidade federativa próxima. Tipicamente, um prefeito de um município não está preocupado com o transbordamento de suas decisões de políticas públicas, o que faz com que as provisões de bens e serviços públicos decididas de forma descentralizada tendam a não ser ótimas do ponto de vista social agregado.

3 Um exemplo bastante debatido é a divisão dos recursos do Fundo de Participação dos Municípios (FPM), cujo desenho beneficia particularmente os municípios pequenos (com menos de 10.500 habitantes) em detrimento dos grandes centros, em especial aqueles situados em periferias metropolitanas (municípios com grande demanda por serviços públicos). Devido a esse viés em favor de municípios pequenos, o desenho do FPM tem estimulado a proliferação de municípios no Brasil (Teixeira et al. 2002, Bugarin e Gadelha 2020), em movimento contrário àquele de amalgamação que está ocorrendo nos países mais avançados (Dollery e Yamazaki 2018).

4 Por exemplo, o Programa Nacional de Alimentação Escolar (PNAE), o Programa Nacional de Apoio ao Transporte Escolar (PNATE), o Programa Dinheiro Direto na Escola (PDDE), entre outros. 
Além dessas transferências obrigatórias, os governos federal e estadual utilizam transferências voluntárias que são operacionalizadas por meio de convênios, contratos de repasse, ou outros instrumentos congêneres. Os recursos repassados via transferências voluntárias podem contemplar os municípios por meio de proposta do Poder Executivo via Lei Orçamentária Anual (LOA) - municípios explicitamente contemplados no Orçamento Geral da União (OGU) ou aqueles que pertencem a alguma região contemplada - ou por meio de emendas parlamentares a essa proposta de Lei Orçamentária do Poder Executivo. Além das emendas individuais, o Congresso pode apresentar outros dois tipos de emendas, as coletivas e as dos relatores. As emendas coletivas podem ser apresentadas por bancadas estaduais e regionais ou por meio de comissões, enquanto as emendas dos relatores podem ser de autoria do relator geral ou dos relatores parciais.

Com efeito, é justamente por intermédio das emendas parlamentares à LOA que os congressistas participam de forma ativa do planejamento do orçamento federal e desempenham um importante papel na interligação entre o governo federal e os governos locais.

Nesse contexto, as transferências voluntárias, por definição, possuem um forte componente político, tanto por parte do Poder Executivo nacional, que tem a prerrogativa de executá-las, quanto do Poder Legislativo federal, que tem a prerrogativa de alocar esses recursos nas áreas de seu interesse.

A legislação e a execução prática do orçamento da União, em geral, são caracterizadas pelo orçamento autorizativo das despesas, na qual parte destas despesas pode ser contingenciada, isto é, o governo não tem a obrigação de realizar tudo o que está expresso na LOA. No que diz respeito às emendas parlamentares, até 2014 as despesas previstas também eram de execução discricionária e não necessariamente eram realizadas pelo Poder Executivo.

A partir do exercício financeiro de 2015, instituiu-se legalmente o regime do "orçamento impositivo" em relação às emendas individuais pela Emenda Constitucional $n^{\circ} 86 / 2015$, as quais passaram a ser consideradas de execução obrigatória até o limite de $1,2 \%$ da receita corrente líquida realizada no exercício anterior. Indo além, a Emenda Constitucional $\mathrm{n}^{\mathrm{o}}$ 100/2019 instituiu o orçamento impositivo, em até 1\% da receita corrente líquida realizada no exercício anterior, também para as emendas das bancadas estaduais. O Poder Executivo somente poderá deixar de executá-las diante da ocorrência de impedimentos técnicos ou caso se verifique que a 
reestimativa da receita e da despesa possa resultar no descumprimento da meta de resultado fiscal estabelecida na Lei de Diretrizes Orçamentárias (LDO). ${ }^{5}$

Assim, à medida que se expandem as hipóteses de emendas impositivas, maior poder de alocação de recursos recai sobre os deputados federais.

\subsection{Panorama das Transferências Voluntárias entre 2001 e 2012}

De forma a conciliar competências constitucionais comuns entre a União, os estados, o Distrito Federal e os municípios, a União realiza transferências voluntárias de recursos para os estados e municípios. Conforme já exposto, a operacionalização dessas transferências, em geral, acontece por meio de convênios ou contratos de repasses, os quais proporcionam relevante flexibilidade e poder para lidar com situações específicas ou imprevistas do contexto econômico e político (Mendes et al. 2008). No que se segue, utiliza-se o termo convênio de forma genérica, referindo-se aos demais instrumentos de transferências voluntárias de recursos, como o contrato de repasse, termo de parceria, termo de fomento e termo de colaboração.

\footnotetext{
${ }^{5}$ Art. 166. § 11, 12, 13 e 18, da CF/88.
} 
Tabela 1 - Características dos Convênios Firmados por Ministério entre 2001 e 2012

\begin{tabular}{|c|c|c|c|c|c|c|}
\hline Ministério & $\begin{array}{l}\text { Montante Total } \\
\text { Firmado }\end{array}$ & $\begin{array}{l}\text { Valor Máximo } \\
\text { Firmado }\end{array}$ & $\begin{array}{l}\text { Valor } \\
\text { Mínimo } \\
\text { Firmado }\end{array}$ & 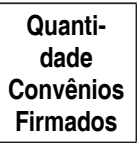 & $\begin{array}{l}\text { Valor Médio } \\
\text { Convênios } \\
\text { Firmados }\end{array}$ & $\begin{array}{c}\% \\
\text { firmados }\end{array}$ \\
\hline Cidades & 35720036454,89 & 687271808,00 & 3369,32 & 34724 & 1028684,38 & $32,473 \%$ \\
\hline Saúde & 0488911642,44 & 160697744,00 & 4803,81 & 43521 & 470782,18 & $18,627 \%$ \\
\hline Integração Social & 9505206665,18 & 257463904,00 & 14827,98 & 10299 & 922925,20 & $8,641 \%$ \\
\hline Turismo & 9253674460,47 & 74416128,00 & 8006,35 & 19916 & 464635,19 & $8,413 \%$ \\
\hline Educação & 8506931868,37 & 86844424,00 & 998,71 & 22804 & 373045,60 & $7,734 \%$ \\
\hline Energias & 5135069320,37 & 97561992,00 & 1209,45 & 14315 & 358719,47 & $4,668 \%$ \\
\hline $\begin{array}{l}\text { Agricultura, Pesca e } \\
\text { Abastecimento }\end{array}$ & 4530414625,12 & 16235287,00 & 8461,84 & 17661 & 256520,84 & $4,119 \%$ \\
\hline Trabalho & 3257759698,46 & 168864240,00 & 14317,09 & 301 & 10823121,92 & $2,962 \%$ \\
\hline $\begin{array}{l}\text { Desenvolvimento } \\
\text { Agrário }\end{array}$ & 3107819377,68 & 10677935,00 & 4812,74 & 10123 & 307005,76 & $2,825 \%$ \\
\hline $\begin{array}{l}\text { Desenvolvimento } \\
\text { Social }\end{array}$ & 3002286026,14 & 88474944,00 & 242,18 & 12996 & 231016,16 & $2,729 \%$ \\
\hline Trabalho & 1862671269,73 & 133380064,00 & 48013,40 & 894 & 2083524,91 & $1,693 \%$ \\
\hline Cultura & 1647865855,19 & 29707534,00 & 3676,31 & 1759 & 936819,70 & $1,498 \%$ \\
\hline Defesa & 1263210064,38 & 28578542,00 & 44587,38 & 1776 & 711266,92 & $1,148 \%$ \\
\hline Justiça & 877382256,03 & 67484352,00 & 7279,89 & 1033 & 849353,58 & $0,798 \%$ \\
\hline Ciência e Tecnologia & 768273001,78 & 32680300,00 & 16012,70 & 1382 & 555913,89 & $0,698 \%$ \\
\hline $\begin{array}{l}\text { Desenvolvimento } \\
\text { indústria e Comércio } \\
\text { Exterior }\end{array}$ & 557438053,48 & 66764852,00 & 40031,75 & 818 & 681464,61 & $0,507 \%$ \\
\hline $\begin{array}{l}\text { Presidência da } \\
\text { República }\end{array}$ & 407387403,87 & 161023664,00 & 8060,92 & 1003 & 406168,89 & $0,370 \%$ \\
\hline Comunicações & 58746299,9 & 5809447,50 & 25584,97 & 278 & 211317,62 & $0,053 \%$ \\
\hline Relações Exteriores & 37232136,00 & 37232136,00 & 37232136,00 & 1 & 37232136,00 & $0,034 \%$ \\
\hline $\begin{array}{l}\text { Planejamento e } \\
\text { Orçamento }\end{array}$ & 4815371,23 & 2280984,30 & 330163,63 & 3 & 1605123,74 & $0,004 \%$ \\
\hline Minas e Energias & 4524588,23 & 578521,19 & 50771,09 & 25 & 180983,52 & $0,004 \%$ \\
\hline
\end{tabular}

Fonte: Tabela elaborada pelos autores com dados da Secretaria do Tesouro Nacional.

Nota: Os valores são deflacionados com a utilização do índice IPCA para o ano de 2014.

/1: \% Firmados se refere ao valor de convênios firmados para o ministério específico em porcentagem do montante total firmado. 
Os repasses via convênios públicos, no período entre 2001 e 2012, alcançaram o montante de quase $R \$ 110$ bilhões de reais $(R \$ 109.997 .656 .438,94)$ em um total de quase $\mathrm{R} \$ 200$ mil ( $\mathrm{R} \$ 1$ 195.632,00) convênios firmados. Setorialmente, mais de $50 \%$ do montante total foi firmado por meio de apenas dois Ministérios: Cidades (32\%) e Saúde (19\%), se verifica na Tabela 1.

Em virtude da característica autorizativa das emendas orçamentárias até a EC n ${ }^{\circ} 86 / 2015$, observou-se casamento entre valores de convênios autorizados e aqueles efetivamente executados em alguns períodos e descasamento em outros, sobretudo a partir de 2010, quando foi intenso o uso de mecanismos de contingenciamento pelo Poder Executivo federal, se verifica no Gráfico 1.

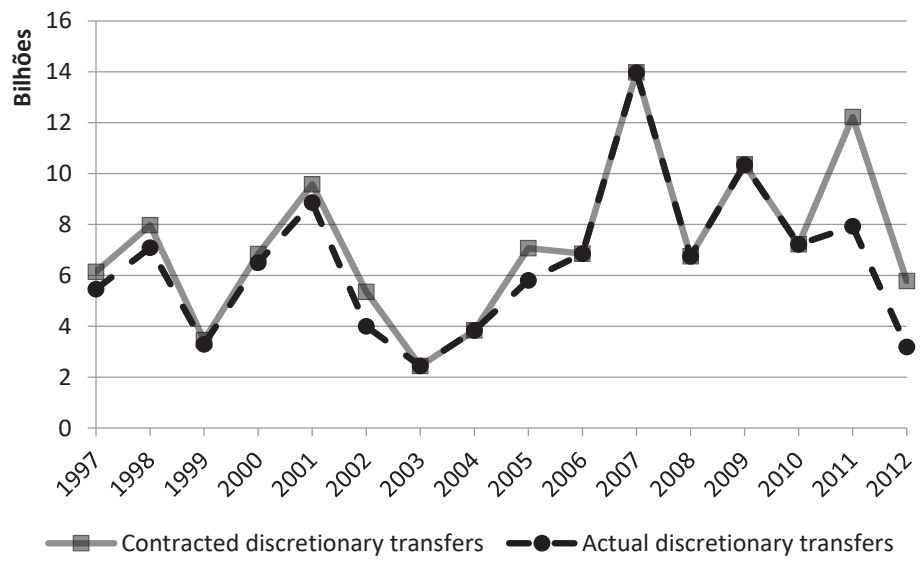

Gráfico 1 - Montante anual de convênios firmados e convênios executados (em bilhões de reais de 2012)

Fonte: Bugarin e Marciniuk (2017).

\section{Literatura Relacionada}

\subsection{Literatura sobre Transferências Voluntárias}

As discussões envolvendo as transferências voluntárias têm ganhado cada vez mais espaço na literatura e nos debates políticos nacionais, parte discutindo seus impactos positivos nas esferas política e econômica e parte 
apontando suas características catalisadoras de corrupção (Sodré e Alves 2010). Os argumentos em defesa das transferências voluntárias, em particular das emendas parlamentares, partem da ideia de que elas são essenciais para que o governo federal alcance a sua governabilidade perante o parlamento (Pereira e Mueller 2002, 2003), são um reforço ao vínculo entre representantes e representados (Pereira e Rennó 2001) e são importantes na redução das desigualdades regionais no Brasil (Carvalho 2009).

Em oposição, o principal ponto negativo levantado pela literatura especializada refere-se ao caráter essencialmente clientelista dessa forma de transferência. Neste contexto, os deputados e senadores podem usar seu poder político para solicitar aos ministérios a liberação de verba para os estados, as regiões ou municípios que representam, com objetivos puramente políticos e eleitoreiros, de maneira que as regiões mais necessitadas tenderiam a ficar de fora da lista dos beneficiados. Desse modo, as transferências beneficiariam apenas os municípios com maior força política dentro do Congresso. Mainwaring (1991) defende que o uso político dos recursos públicos nas formas de patronagem, clientelismo e patrimonialismo gera um alto custo para a economia do país e também para a legitimidade do sistema político. ${ }^{6}$

Quanto à capacidade de direcionamento do poder Executivo nas transferências voluntárias, existe abundante literatura internacional sugerindo que existe um viés partidário nessas transferências. Segundo essa literatura, os montantes dessas transferências aumentam quando o partido do prefeito é o mesmo que o partido do presidente, um fenômeno conhecido como transferências partidárias ou "partisan transfers" (Wright 1974, Ansolabehere e Snyder 2006 (EUA); Gonschorek et al. 2018 (Indonésia); Khemani 2003, 2007 (Índia); Kraemer 1997 (México); Porto e Sanguinetti 2001 (Argentina); Rozevitch e Weiss 1993 (Israel); Solé-Ollé e SorribasNavarro 2008 (Espanha); Tamura 2010 (Japão); Veiga e Pinho 2007 (Portugal)).

6 O ex-presidente Fernando Henrique Cardoso chama atenção sobre o efeito negativo da sistemática orçamentária no que se refere às emendas parlamentares, sobre a legitimidade do governo. Para o ex-presidente, "por menores que sejam os recursos de transferências via emendas, estas infectam a percepção do uso de recursos públicos, pois são noticiadas com alarido, como se tudo fosse clientelismo e todo clientelismo em si mesmo fosse corrupção. O resultado perverso disso é que os ministros ou gestores públicos incumbidos da relação com os parlamentares sofrem considerável desgaste, na medida em que não cedem às pressões. E quando cedem, ainda que nos limites da lei e do moralmente aceitável, veem-se associados às piores práticas" (Cardoso 2006). 
Para o caso do Brasil, desde os trabalhos precursores de Ferreira e Bugarin (2004, 2007), confirmados com bases de dados mais precisas em Brollo e Nannicini (2012), para o setor de infraestrutura, em Sakurai e Theodoro (2020) para bens de capitais e em Bugarin e Marciniuk (2017) para convênios em geral, têm-se focado, também, em mostrar que municípios cujos prefeitos pertencem ao mesmo partido que o presidente (respectivamente, governador) recebem mais transferências voluntárias do executivo federal (respectivamente, estadual). Ferreira e Bugarin $(2004,2007)$ argumentam que o governo federal tem um compromisso natural com seu próprio partido e uma forma de recompensar aqueles que o apoiaram durante o processo eleitoral é conduzir recursos públicos cuja aplicação é discricionária do governo federal para localidades da base governista.

No que diz respeito ao papel do Legislativo na definição das transferências voluntárias, a literatura internacional tende a focar nos incentivos individuais dos congressistas, que se empenhariam em transferir recursos para projetos em seus distritos correspondentes de modo a receber o retorno dos cidadãos na forma de votos nas eleições subsequentes. ${ }^{7}$ Trata-se da "conexão eleitoral", também conhecida na literatura anglo-saxã com "pork barrel politics". 8

A literatura para o caso brasileiro também tem focado nos interesses individuais dos congressistas (Ames 1995a, 1995b, 2003; Firpo et al. 2015). Mais recentemente, Schneider et al. (2020) contribuem com essa literatura mostrando que a introdução da urna eletrônica no país fortaleceu os incentivos à conexão eleitoral no Legislativo.

No entanto, os autores deste trabalho não têm conhecimento de estudos visando avaliar econometricamente a motivação partidária nas transferências voluntárias oriundas do Legislativo. O presente trabalho tem por objetivo justamente desenvolver essa avaliação.

7 Considerando que nos Estados Unidos e na Austrália os distritos eleitorais são unitários, ou seja, existe apenas um deputado eleito por distrito eleitoral, esse foco nos interesses dos deputados é natural.

8 Vide, por exemplo, Mayhew 1974 e Stein e Bickers 1994 para os Estados Unidos, Golden e Picci 2008 para a Itália e, Veiga e Veiga 2013 para Portugal, entre outros estudos. 


\subsection{O Papel dos Partidos Políticos na Distribuição de Recursos via Transfe- rências Voluntárias no Brasil}

O presente trabalho também se insere no debate atual sobre a força dos partidos na organização interna do Legislativo brasileiro.

De acordo com corrente teórica mais tradicional da ciência política, a legislação eleitoral vigente no país reforça o comportamento individualista dos políticos, tanto na arena legislativa quanto na arena eleitoral, e dificulta a construção de um sistema partidário efetivo (Mainwaring 1991), sobretudo em virtude da adoção de um sistema político de lista aberta com representação proporcional (Silva 2010). ${ }^{9}$ Nessa visão, os partidos não são considerados importantes vínculos entre o eleitorado e o sistema político, sendo os políticos, de forma individual, os principais responsáveis por este vínculo.

Essa interpretação sobre o sistema político brasileiro resulta no argumento de que os deputados, de forma individualizada, tendem a negociar recursos públicos via transferências voluntárias com o Poder Executivo para suas áreas de interesse, os chamados distritos eleitorais informais, ${ }^{10}$ em troca de votos (Ames 1995a, 1995b, 2003). Como resultado, o sucesso de um político dependeria proporcionalmente da quantidade de recursos públicos gasto na sua zona de influência, pois esses recursos garantiriam seu controle político sobre essas regiões e, consequentemente, seriam convertidos em votos nas próximas eleições, independentemente da sua vinculação partidária (Silva 2010, Pereira e Rennó 2001).

Em contraposição a essa corrente tradicional, há uma série de teóricos que apontam para a importância dos partidos políticos na distribuição dos recursos via transferências voluntárias.

Em uma primeira linha de argumentação, há a discussão sobre a existência de um sistema parcial de influência entre as arenas legislativa e eleitoral, em que o papel dos partidos é reduzido na arena eleitoral, mas relevante na atividade parlamentar. De acordo com Pereira e Mueller (2003), as

${ }^{9}$ No Brasil, as eleições para cargos legislativos adotam o sistema de lista aberta. Neste sistema, cabem aos eleitores escolher se querem votar na legenda do partido ou diretamente nos candidatos de sua preferência. Ao final das votações, somam-se os votos recebidos por todos os candidatos de cada partido, adicionando-se ao total os sufrágios dados para a legenda. A quantidade de cadeiras que caberá a cada partido será determinada por uma fórmula (com base no Método D’Hondt), e os candidatos de cada legenda serão ordenados de acordo com o número total de votos que receberam.

${ }^{10}$ Vide, a esse respeito, Ames 2003 ou ainda Silva 2013. 
regras internas do Congresso tornam o comportamento dos parlamentares dependentes da lealdade de seus respectivos partidos, o que os fortalece.

Uma outra corrente já defende a existência de ações mais coordenadas entre os legisladores e seus partidos, inclusive na arena eleitoral, havendo motivações de influência partidária na elaboração de emendas parlamentares (Figueiredo e Limongi 2002, 2008; Nicolau 2006, entre outros).

Segundo Figueiredo e Limongi (2008), os deputados não possuem total liberdade para alocar recursos baseados apenas em seus interesses particulares. A alocação das emendas está inteiramente subordinada à proposição orçamentária feita pelo Poder Executivo, em primeiro lugar, e depois está sujeita às determinações do partido por meio de seus líderes no Congresso. Dessa forma, a liberdade do deputado para escolher quais programas pretende emendar (programas previamente propostos) e qual o local que pretende enviar o recurso, estará cerceado se houver diretrizes partidárias que o estimulem a direcionar os recursos para outras regiões (Silva, 2010).

Segundo Pereira e Mueller (2002), a execução das emendas individuais é vista como uma das principais formas disponíveis ao Executivo para negociar suas preferências com sua coalizão no Congresso. Além disso, esse tipo de emenda seria utilizado pelo Congresso como uma moeda de troca política de baixo custo. Figueiredo e Limongi (2002) ainda ressaltam que, além das emendas individuais, existem as coletivas e as dos relatores, que têm precedência sobre as individuais e possuem maior ingerência da dinâmica partidária. ${ }^{11}$

Neste artigo, seguindo essa última corrente teórica testa-se se os convênios firmados entre a União e os municípios são passíveis de influência partidária em todos os âmbitos do governo federal e municipal.

${ }^{11}$ Vale notar, ademais, que em 26 de junho de 2019 foi promulgada a 100ª emenda à Constituição brasileira, "que prevê a execução obrigatória de emendas das bancadas estaduais no Orçamento da União", confirmando a importância do caráter coletivo dado pelo Congresso Nacional às emendas (vide: https://wwwl2.senado.leg.br/noticias/materias/2019/06/26/orcamento-impositivo-para-emenda-de-bancada-e-promulgado-pelo-congresso). 


\section{Análise Econométrica}

Esta seção pretende analisar empiricamente os efeitos da identidade partidária entre os entes governamentais e legisladores na distribuição de rendas via transferências voluntárias, por meio de convênios públicos e contratos de repasses federais, para os municípios.

As análises utilizam um painel de dados não balanceado ${ }^{12}$ com 5.568 municípios para os anos de 2001 a 2012, englobando três ciclos eleitorais municipais completos, método esse que oferece um contraponto em termos de validade externa à análise desenvolvida em Brollo e Nannicini (2012). No entanto, é importante ressaltar aqui que uma análise baseada na metodologia de regressão descontínua em muito complementaria e enriqueceria os resultados encontrados; essa abordagem é deixada aqui como uma sugestão para pesquisas futuras.

As variáveis de interesse foram construídas com dados do Tribunal Superior Eleitoral para os vários níveis de governo.

\subsection{As Variáveis de Interesse}

A principal variável de interesse é a identidade partidária entre o Poder Executivo do município $i$ no tempo $t$ e o Poder Legislativo Federal no mesmo período $t$ (Id. $\operatorname{Leg}_{i t}$ ). Trata-se de uma variável dummy que assume o valor 1 se o município pertencer a uma área de concentração de votos de um dado partido e o prefeito deste município pertencer ao partido em questão.

Para calcular essa área de influência do partido político utiliza-se o Quociente Locacional, criado por Bendavid-Val (1991) e adaptado para a economia política por Silva \& Davidian (2013), sendo capaz de medir a concentração dos votos recebidos pelo deputado em cada município, controlando-se pelo tamanho relativo dos municípios dentro de seu respectivo estado. Dessa forma, o índice mensura em quantos municípios o deputado concentrou os seus votos e será medido da seguinte forma:

12 O painel é não balanceado devido essencialmente ao fato de que nem todos os municípios fornecem os dados solicitados pela Secretaria do Tesouro Nacional e que são usados para a construção do FINBRA. 


$$
Q L_{j i}=\frac{\frac{V_{j i}}{V_{j}}}{\frac{V_{i}}{V}}
$$

Sendo $V_{j i}$ o total de votos do partido $j$ no município $i, V_{i}=\sum_{j} V_{j i}$ o total de votos no município $i, V_{j}=\sum_{i} V_{j i}$ o total de votos do partido $j$ e $V=\sum_{i} \sum_{j} V_{j i}$ o total de votos em toda a região (estado ou microrregião). Dessa forma, considerando uma distribuição homogênea, este indicador permite a comparação dos votos obtidos por município em termos relativos (Silva \& Davidian 2013).

Por exemplo, se a alocação espacial dos votos de todos os candidatos fosse homogeneamente distribuída, uma cidade com $1 \%$ do total dos eleitores do estado deveria contribuir com $1 \%$ dos votos para todos os candidatos em uma dada eleição; considera-se que se um deputado receber 10.000 votos, $1 \%$ (100 votos) desses votos seriam provenientes daquele município. Isto implica um $\mathrm{Q} L$ igual a 1. Caso o deputado tenha recebido 450 votos naquela cidade, o $Q L$ indicará 4,5 , já que ele recebeu 4,5 vezes o número de votos esperado em uma distribuição homogênea. No entanto, apesar de este índice mensurar apropriadamente o nível de concentração de votos por candidato e por município, ele não permite inferir diretamente se o candidato tem votação mais ou menos concentrada no município, i.e., apenas permite analisar qual a relação entre os votos esperados e os votos recebidos por cada candidato em cada um dos municípios isoladamente.

Assim, a variável identidade partidária entre o Poder Executivo do município $i$ no tempo $t$ e o Poder Legislativo Federal no tempo $t$ é dada por:

Id. Leg $_{i t}= \begin{cases}1 & \text { se o partido do prefeito no município } i \text { no período } t \text { for } j \text { e } Q L_{j i}>1(2) \\ 0 & \text { caso contrário }\end{cases}$

Ou seja, a Id. Leg $i t$ será igual a 1 (um) se o partido gestor do município $i$ for igual ao partido $j$ e esse partido tiver um quociente locacional no município $i$ maior do que um. Isso não significa necessariamente que o prefeito estará atuando em sua área de influência partidária, dado que o QL captura dados das eleições para o Legislativo federal, enquanto as eleições municipais podem derivar de outras alianças partidárias, já que não há verticalização na legislação eleitoral. ${ }^{13}$

${ }^{13}$ Os autores desenvolveram uma análise gráfica por município e por partido do indicador QL para as 
De forma a poder dialogar com a literatura mais tradicional que foca no papel do Executivo federal, incluem-se também variáveis de identidade partidária entre os diferentes níveis do poder executivo:

Id. Pres $_{i t}= \begin{cases}1 & \text { se o partido do prefeito no município } i \text { e do presidente forem os mesmos no perído } t \\ 0 & \text { caso contrário }\end{cases}$

Id. Coa. Pres $i t \begin{cases}1 & \text { se o partido do prefeito no município } i \text { pertence à coalizão nacional de apoio ao presidente } \\ 0 & \text { caso contrário }\end{cases}$

Portanto, Id. Pres $i t$ será igual a 1 (um) se o partido do prefeito do município $i$ no ano $t$ for igual ao partido do presidente no ano $t$. Da mesma forma, Id. Coa. Pres ${ }_{i t}$ será 1 (um) se o partido do prefeito do município $i$ no ano $t$ pertencer à coalizão do partido do presidente no ano $t$. A variável dummy que representa os governos estaduais $\left(\mathrm{Id} . \mathrm{Gov}_{i t}\right.$ ) segue a mesma lógica da variável Id. Pres $i t$.

Espera-se que todas essas variáveis de interesse apresentem um efeito positivo sobre as transferências voluntárias indicando a existência de viés político na distribuição de recursos via convênios.

\subsection{As Variáveis de Controle}

Além de envolverem diferentes atores políticos com diferentes interesses, os programas e ações do governo federal possuem diversos critérios técnicos para a priorização da aplicação dos recursos discricionários. Muitas vezes, o nível de desenvolvimento socioeconômico local, as regras e limites impostos pelas instituições orçamentárias, dentre outros motivos, são levados em conta para a efetivação dos convênios e contratos de repasse. Dessa forma, além da análise principal, pretende-se verificar se essas transferências são influenciadas por outras condições políticas do ente, pelas características sociais dos municípios, pelas regras institucionais impostas ao recebimento dessas verbas e pelas características pessoais dos prefeitos. Todas as variáveis de controle utilizadas nas análises foram construídas como em Marciniuk e Bugarin (2019).

eleições de 2006 e de 2010. Por limitação de espaço, essa análise não foi incluída neste artigo, mas encontra-se à disposição do leitor interessado sob demanda aos autores. 


\section{Características Políticas dos Municípios}

Nível de competição eleitoral para o Legislativo Federal (Taagepera): Para se analisar o nível de competição política em um dado município, Taagepera (1979) propõe um indicador de desequilíbrio eleitoral que reflete o desequilíbrio das disputas eleitorais em cada cidade:

$$
\text { Taagepera }=T_{m}=\frac{\sum_{i=1}^{\infty}\left[\frac{\left(P_{i, m}-P_{i+1, m}\right)}{i}\right]-H_{m}^{2}}{\sqrt{H_{m}}-H_{m}^{2}}
$$

$T_{m}$ é o índice de desequilíbrio para a cidade $m, P_{i, m}$ é o percentual de votos do $i$-ésimo candidato à Câmara dos Deputados (Federal) na cidade $m$ e $H_{m}$ é o índice de Herfindahl-Hirschman ${ }^{14}$ na cidade $m$. Este índice será incluído na fórmula do índice de desequilíbrio como uma forma de eliminar a "correlação residual" com o próprio termo $\mathrm{H}$, já que o somatório do numerador varia entre os limites de $\sqrt{H}$ a $H^{2}$.

Este indicador pretende mostrar quão disputada é a eleição em um município a partir da ideia de desequilíbrio. Neste contexto, quanto mais desequilibrada for uma votação, menos acirrada será, afinal um dos candidatos tende a desequilibrar a votação em seu favor. Nota-se que os valores de $T_{m}$ pertencem ao intervalo $[0,1]$, e quanto mais próximo de 1 (um), mais desequilibrada é a distribuição de votos naquele município (menos acirrada será a votação no município).

Ideologia Partidária (Ideologia): Esse indicador é construído com base no trabalho de Powell e Zucco (2009), atualizado em Zucco (2014). Esse último trabalho estimou as posições ideológicas dos partidos políticos brasileiros a partir de questionários aplicados aos legisladores federais de 1990 a 2013. As posições ideológicas são dispostas em um intervalo 0 (zero) e 1 (um), em que zero corresponde a extrema esquerda e um a extrema direita. Vale notar que os dados em Zucco (2014) têm periodicidade trienal ou quadrienal, correspondendo às sucessivas edições da pesquisa empírica. Esses dados foram anualizados seguindo a metodologia e os cálculos em Lopez, Bugarin e Bugarin (2015).

${ }^{14} \mathrm{O}$ índice de Herfindahl-Hirschman neste contexto será calculado da seguinte forma: $H_{m}=\frac{\sum_{i} V^{2}{ }_{i, m}}{\left(\sum_{i} V_{i, m}\right)^{2}}$ em que $V_{i, m}$ é o número de votos recebidos pelo candidato $i$ no município $m$. 
$\boldsymbol{G}_{\mathbf{1}} \mathbf{e} \boldsymbol{G}_{\mathbf{2}}$ : Essas variáveis foram utilizadas conforme o trabalho de Marciniuk e Bugarin (2019) e pretendem medir se prefeitos em primeiro mandato com expectativas de permanecer no cargo em um segundo mandato tendem a transferir mais rendas do que seus pares que não vislumbram um segundo mandato. A variável dummy $G_{1}$ será igual a 1 (um) se o prefeito for de primeiro mandato e se, além disso, ele for candidato a reeleição na próxima eleição, e 0 (zero) caso contrário. Essa variável é uma proxy para prefeitos de primeiro mandato com expectativas de se reelegerem na próxima eleição. A variável dummy $G_{2}$ será igual a 1 (um) se o prefeito for de primeiro mandato e, no entanto, não tiver tentado a reeleição, e 0 (zero) caso contrário. Essa variável é uma proxy para os prefeitos de primeiro mandato que não vislumbram um segundo mandato no cargo.

Fragmentação do Legislativo Municipal (Frag.Leg.Mun): Esta variável representa a fragmentação da câmara legislativa municipal e visa medir a influência da coesão/dispersão das preferências dos partidos políticos sobre o desempenho fiscal. Este indicador foi baseado no trabalho de Rae e Taylor (1970) e traduz o grau de concentração dos partidos políticos que compõem a câmara dos vereadores e quanto mais próximo de 1 (um) o valor dessa variável, mais fragmentada (menor a concentração) é a câmara legislativa do município e quanto mais próximo de 0 (zero), mais concentrado.

$$
\text { Frag. Leg. Mun }=1-\sum_{w=j}^{J} v_{w}^{2}
$$

A variável $v_{w}$ é a proporção de cadeiras ocupadas por cada partido na câmara legislativa municipal. Espera-se um efeito negativo dessa variável, uma vez que quanto maior o número de atores políticos envolvidos em uma tomada de decisão, maior a possibilidade de ocorrer paralisia decisória ou ingovernabilidade.

Indicador de Competitividade no Executivo Municipal (Comp.Exec. Mun): Esse indicador mede a influência do nível de disputas para cargos de chefe do executivo nas contas públicas subnacionais. O cálculo do indicador é baseado no inverso do índice de concentração de HerfindhalHirschman e traduz que quanto maior o valor do indicador, maior será a disputa nas eleições:

$$
\text { Comp. Exec. Mun }=\frac{1}{\sum_{k=1}^{m} p_{k}^{2}}
$$


Nessa expressão, $k=1, \ldots, m$ é a quantidade de candidatos que concorrem à eleição e $p_{k}$ é a porcentagem de votos recebidos por cada candidato $k$. Espera-se um sinal positivo para o coeficiente dessa variável, porque quanto maior a competição política no município, maior é o incentivo gerado ao atual gestor para transparecer ao eleitor que possui habilidades e influência para aumentar a arrecadação do município.

Participação Popular (Part.Pop): Esse indicador pretende medir se o interesse e a participação dos eleitores possuem algum efeito na execução das políticas fiscais locais. O indicador é construído como a proporção entre os votos válidos e os votos brancos e nulos no município na eleição municipal imediatamente anterior ao ano $t$. Embora os votos brancos e nulos possam ser interpretados como uma forma de protesto contra o governo, eles podem ser boas proxies para o desinteresse político e para a falta de informação a respeito dos candidatos, pelo eleitorado. Dessa forma:

$$
\text { Part. Pop }=\frac{Q_{v i}}{Q_{b i}+Q_{n i}}
$$

Na expressão acima, $Q_{v i}$ é a quantidade de votos válidos, $Q_{b i}$ é a de votos brancos e $Q_{n i}$ é a de votos nulos no município $i$ na eleição imediatamente anterior ao ano $t$. Espera-se um efeito positivo no total de convênios recebidos.

\section{Características dos Candidatos}

Este conjunto de variáveis visa capturar o efeito das características pessoais do prefeito do município diante das decisões tomadas na política fiscal. O conjunto consiste das variáveis Sexo do Prefeito (Sexo), Idade do Prefeito (Idade) e Instrução do Prefeito (Escolaridade). Essas variáveis foram coletadas junto ao Tribunal Superior Eleitoral para os pleitos de 2000, 2004, 2008 e 2012.

\section{Características Fiscais dos Municípios}

Este conjunto de variáveis visa controlar pelas características fiscais do município. Arrecadação (Receita): a razão entre o Montante de Receitas 
Próprias do município e a Receita Corrente Líquida; Gastos com Pessoal (Pessoal): o montante das Despesas com Pessoal do município em porcentagem da receita corrente líquida; Gastos com investimentos (Investimento): o montante das despesas com investimento de capital do município em porcentagem da receita corrente líquida; Transferências Obrigatórias (Transf.Obrig): Montante das transferências legais e obrigatórias recebidas pelo município em porcentagem da receita corrente líquida; e Restos a pagar (Restos): Montante das Despesas Inscritas nos Restos a Pagar do município em porcentagem dos Ativos Financeiros.

\section{Características Sociodemográficas dos Municípios:}

Este conjunto de variáveis visa controlar pelas características sociodemográficas dos municípios e foram coletadas junto ao IBGE. São elas: Expectativa de vida (Expec.Vida), Taxa de analfabetismo (Analfabetismo), Taxa de pobreza (Pobreza) e População (Pop).

A Tabela 2 descreve de forma sucinta todas as variáveis de controle utilizadas nos testes empíricos e apresenta suas estatísticas descritivas respectivas.

Tabela 2 - Descrição das variáveis de controle e suas estatísticas descritivas

\begin{tabular}{|c|c|c|c|c|c|}
\hline Variáveis & Descrição das Variáveis & Média & $\begin{array}{l}\text { Desvio } \\
\text { Padrão }\end{array}$ & Mín & Máx \\
\hline & Variáveis de interesse & & & & \\
\hline Id.Leg & $\begin{array}{l}\text { Medida de Igualdade partidária entre o Poder Legislativo Fe- } \\
\text { deral e o Poder Executivo Municipal. }\end{array}$ & 0.6061 & 0.48862 & 0 & 1 \\
\hline Id.Pres & $\begin{array}{l}\text { Medida de Igualdade partidária entre o Poder Executivo Muni- } \\
\text { cipal e o Poder Executivo Federal. }\end{array}$ & 0.0933 & 0.29085 & 0 & 1 \\
\hline Id.Coa.Pres & $\begin{array}{l}\text { Medida de Igualdade partidária entre o Poder Executivo Muni- } \\
\text { cipal e a Coalizão do Poder Executivo Federal. }\end{array}$ & 0.1091 & 0.31199 & 0 & 1 \\
\hline Id.Gov & $\begin{array}{l}\text { Medida de Igualdade partidária entre o Poder Executivo Muni- } \\
\text { cipal e o Poder Executivo Estadual. }\end{array}$ & 0.1965 & 0.39737 & 0 & 1 \\
\hline \multicolumn{6}{|c|}{ Características Políticas dos Municípios (Políticos) } \\
\hline Taagepera & $\begin{array}{l}\text { Indicador de Taagepera. Esse índice mede o desequilíbrio da } \\
\text { disputa eleitoral para o Legislativo Nacional em cada munici- } \\
\text { pio. Quanto maior for o índice, menor é a competitividade, ou } \\
\text { seja, menos acirrada é a disputa eleitoral. }\end{array}$ & 0.4943 & 0.2337 & 0 & 0.95 \\
\hline G1 & $\begin{array}{l}\text { Grupo de prefeitos em primeiro mandato e que concorreram } \\
\text { à reeleição. }\end{array}$ & 0.4612 & 0.4985 & 0 & 1 \\
\hline
\end{tabular}


Tabela 2 - Descrição das variáveis de controle e suas estatísticas descritivas (Cont.)

\begin{tabular}{|c|c|c|c|c|c|}
\hline G2 & $\begin{array}{l}\text { Grupo de prefeitos em primeiro mandato não candidatos nas } \\
\text { eleições subsequentes. }\end{array}$ & 0.212 & 0.4089 & 0 & 1 \\
\hline Ideologia & $\begin{array}{l}\text { Ideologia partidária - posição ideológica dos partidos. Este in- } \\
\text { dicador é construído com base no trabalho de Powell e Zucco } \\
\text { (2009) }\end{array}$ & 5.0411 & 1.2104 & 2.13 & 6.87 \\
\hline $\begin{array}{l}\text { Frag.Leg. } \\
\text { Mun }\end{array}$ & $\begin{array}{l}\text { Indicador de fragmentação no Legislativo local - representa } \\
\text { a fragmentação da câmara legislativa municipal e indicará a } \\
\text { influência da coesão/dispersão das preferências dos partidos } \\
\text { políticos sobre o desempenho fiscal. }\end{array}$ & 0.744 & 0.09847 & 0 & 0.942 \\
\hline $\begin{array}{l}\text { Comp.Exec. } \\
\text { Mun }\end{array}$ & $\begin{array}{l}\text { Indicador de competitividade no Executivo local - mede o } \\
\text { quanto as disputas para cargos de chefe do Executivo são } \\
\text { acirradas em nível municipal. }\end{array}$ & 2.217 & 0.6736 & 1 & 10.42 \\
\hline Part.Pop & $\begin{array}{l}\text { Participação popular - proxies para o desinteresse político } \\
\text { e para a falta de informação a respeito dos candidatos, pelo } \\
\text { eleitorado. O indicador pretende medir se o interesse e a parti- } \\
\text { cipação dos eleitores possuem algum efeito na execução das } \\
\text { políticas fiscais locais. }\end{array}$ & 81.089 & 8.70222 & 9.16 & 98.14 \\
\hline \multicolumn{6}{|c|}{ Características pessoais do Prefeito (Pessoais) } \\
\hline Sexo & Sexo do Prefeito & 0.916 & 0.2775 & 0 & 1 \\
\hline Idade & Idade do Prefeito & 48.488 & 9.70683 & 0 & 88 \\
\hline Escolaridade & Escolaridade do Prefeito & 4,65 & 1,72 & 1 & 7 \\
\hline Receita & $\begin{array}{l}\text { Montante de Receitas Próprias do município em porcentagem } \\
\text { da receita corrente líquida. }\end{array}$ & 0.18384 & 0.17191 & -0.17 & 5.88 \\
\hline Pessoal & $\begin{array}{l}\text { Montante das Despesas com Pessoal do município em por- } \\
\text { centagem da receita corrente líquida. Pretende captar o gasto } \\
\text { fixo do governo pois este gasto é difícil de ser modificado em } \\
\text { curto espaço de tempo. }\end{array}$ & 0.47053 & 0.13879 & 0 & 26.54 \\
\hline Investimento & $\begin{array}{l}\text { Montante das Despesas com Investimento de Capital do mu- } \\
\text { nicípio em porcentagem da receita corrente líquida. Pretende } \\
\text { captar os gastos com investimentos e infraestrutura para a } \\
\text { sociedade local. }\end{array}$ & 0.12117 & 0.09399 & 0 & 4.32 \\
\hline Transf.Obrig & $\begin{array}{l}\text { Montante das Transferências Legais e Obrigatórias recebidas } \\
\text { pelo município em porcentagem da receita corrente líquida. }\end{array}$ & 0.92239 & 0.12928 & -0.08 & 3.83 \\
\hline Restos & $\begin{array}{l}\text { Montante das Despesas Inscritas nos Restos a Pagar do mu- } \\
\text { nicípio em porcentagem dos Ativos Financeiros. }\end{array}$ & 3.7819 & 420.136 & -1101.66 & 105895.2 \\
\hline \multicolumn{6}{|c|}{ Características Sociodemográficas dos Municipais (Sociais) } \\
\hline Expec.Vida & Indicador de expectativa de vida municipal. & 71.2737 & 3.65596 & 57.46 & 79.93 \\
\hline $\begin{array}{l}\text { Analfabe- } \\
\text { tismo }\end{array}$ & Indicador de Analfabetismo municipal. & 18.1113 & 10.9401 & 0.752 & 58.23 \\
\hline Pobreza & Indicador de Pobreza municipal. & 29.4230 & 20.4776 & -10.8 & 88.65 \\
\hline Pop & População municipal. & 32230.8 & 194003.7 & 800 & $1.14 e^{7}$ \\
\hline
\end{tabular}

Fonte: Elaboração própria. 


\subsection{Resultados Empíricos}

Os métodos em painel foram escolhidos com o intuito de avaliar o desempenho real dos indicadores de transferências de renda ao longo do tempo. Uma das grandes vantagens dessa metodologia é o controle da endogeneidade decorrente de variáveis omitidas (relacionadas com os eleitores ou com as localidades) fixas no tempo e correlacionadas com os regressores. Cita-se como exemplos, algumas características institucionais do município que podem estar correlacionadas tanto com uma maior arrecadação desses recursos voluntários quanto com os índices sociais.

De fato, o teste $\mathrm{F}$ de Chow ${ }^{15}$ revelou um estatístico $F(21,5431)=48,55$ com p-valor de 0,0000 , indicando que um modelo de painel com efeitos fixos é superior a um modelo de OLS empilhado (POLS). Em seguida, o teste de Hausman gerou um estatístico $\chi^{2}(21)=1599,15$ com $p$-valor de 0,0000, indicando que o modelo de painel com efeitos fixos é superior ao modelo de painéis com efeitos aleatórios. Ademais, o teste de Wald modificado para avaliação de heterocedasticidade por grupo em modelos de efeitos fixos em que o estatístico resultante foi $\chi^{2}(5432)=67 \times 10^{7} \mathrm{com}$ p-valor de 0,0000 rejeita a hipótese de homocedasticidade. ${ }^{16}$

Adota-se, portanto, o modelo de painel com efeitos fixos com erro padrão robustos à heterocedasticidade, com controle para as especificidades temporais por dummies anuais bem como dummies de estado-ano conforme descrito abaixo, em que o índice $i$ refere-se ao município enquanto o índice $t$ refere-se ao ano e $u_{i t}$ corresponde ao erro.

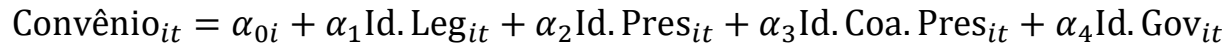

$$
\begin{aligned}
& +\beta \text { Politicos }_{i t}+\sigma \text { Pessoais }_{i t}+\rho \text { Fiscais }_{i t}+\pi \text { Sociais }_{i t}+\gamma \text { Ano } \\
& +\delta \text { EstadoAno }+u_{i t}
\end{aligned}
$$

${ }^{15} \mathrm{O}$ teste de Chow compara resultados quando se consideram grupos separadamente ou conjuntamente, e assim verifica-se se vale a pena utilizar o método de efeitos fixos ou de POLS. Ou seja, o teste compara os resultados quando consideramos diferentes grupos (um grupo por período, que engloba os efeitos de painel) ou o agrupamento de grupos (o que ocorre em POLS).

${ }^{16} \mathrm{O}$ teste de Breusch-Pagan/Cook-Weisberg de heterocedasticidade aplicado ao modelo POLS calculou um estatístico $\chi^{2}(1)=108456,50$ novamente com p-valor associado de 0,0000 , também rejeitando a hipótese nula de homocedasticidade. 
$\mathrm{Na}$ expressão acima, Ano congrega todas as variáveis dummies de ano e Estado Ano engloba todas as variáveis dummies de estado-ano. ${ }^{17}$

A Tabela 3 sintetiza os diversos coeficientes obtidos para a variável referente ao montante dos convênios recebido pelos municípios per capita em quatro contextos distintos, em que parte-se da regressão mais simples com apenas as principais variáveis de interesse e adicionam-se sucessivamente variáveis de controle: Modelo 1 (sem controles, com tendência temporal e efeitos fixos); Modelo 2 (adicionando-se controles de variáveis políticas); Modelo 3 (adicionando controles de variáveis pessoais do prefeito) e Modelo 4 (modelo completo, adicionando-se variáveis fiscais e sociodemográficas). Estes testes têm o objetivo de medir a importância dos grupos das covariadas para a robustez do modelo. Os erros-padrão robustos encontram-se incluídos entre parênteses.

Os resultados da Tabela 3 revelam que a inclusão dos outros grupos de variáveis de controle mantém a significância dos coeficientes e não apresenta alteração considerável nos resultados, sugerindo que o conjunto de controles utilizado possui o potencial de captar razoavelmente bem a heterogeneidade dos entes da amostra, promovendo adequado tratamento ao problema de simultaneidade e indicando a robustez do modelo. Mais ainda, a introdução dos controle sucessivos aumentou a significância geral das regressões, passando o valor do R-quadrado de $11,2 \%$ para $13,3 \%$ e, de forma mais importante, aumentou a significância e a intensidade (se comparado ao modelo 1) do efeito da variável de interesse Id.Leg sobre o montante total per capita de recursos recebidos pelo município.

${ }^{17}$ Agradecemos a um parecerista anônimo por sugerir a inclusão destas últimas variáveis. 
Tabela 3 - Regressão para o modelo de painel com efeitos fixos e erros-padrão robustos. Variável dependente: Montante de recursos recebidos por município por ano per capita

\begin{tabular}{|c|c|c|c|c|}
\hline Variáveis de Controle & Modelo 1 & Modelo 2 & Modelo 3 & Modelo 4 \\
\hline \multirow[t]{2}{*}{ Id.Leg } & $2,22^{*}$ & $3,70^{* *}$ & $3,78^{* *}$ & $3,24^{* *}$ \\
\hline & $(1,37)$ & $(1,54)$ & $(1,627)$ & $(1,54)$ \\
\hline \multirow[t]{2}{*}{ Id.Pres } & $12,34^{\star \star *}$ & $9,14^{* * *}$ & $8,63^{\star * *}$ & $7,43^{\star \star *}$ \\
\hline & $(1,56)$ & $(1,69)$ & $(1,69)$ & $(1,65)$ \\
\hline \multirow[t]{2}{*}{ Id.Coa.Pres } & 1.84 & $-1,25$ & $-1,23$ & $-1,85$ \\
\hline & $(1,47)$ & $(2,61)$ & $(2,61)$ & $(2,61)$ \\
\hline \multirow[t]{2}{*}{ Id.Gov } & $-6,61^{\star \star *}$ & $-6,21^{* \star *}$ & $-6,21^{\star \star *}$ & $-7,24^{\star \star \star}$ \\
\hline & $(0,99)$ & $(1,08)$ & $(1,08)$ & $(1,09)$ \\
\hline \multirow[t]{2}{*}{ Taagepera } & & 1,91 & 1,86 & 1,37 \\
\hline & & $(1,99)$ & $(1,99)$ & $(2,04)$ \\
\hline \multirow[t]{2}{*}{ G1 } & & $8,47^{\star * *}$ & $7,60^{\star * *}$ & $8,03^{* * *}$ \\
\hline & & $(1,19)$ & $(1,17)$ & $(1,20)$ \\
\hline \multirow[t]{2}{*}{ G2 } & & $-6,36^{\star \star *}$ & $-6,36^{* * *}$ & $-3,32^{*}$ \\
\hline & & $(1,64)$ & $(1,63)$ & $(1,88)$ \\
\hline \multirow[t]{2}{*}{ Ideologia } & & $-1,90^{\star \star \star}$ & $-1,76^{\star \star \star}$ & $-2,25^{\star \star \star}$ \\
\hline & & $(0,57)$ & $(0,57)$ & $(0,55)$ \\
\hline \multirow[t]{2}{*}{ Comp.Exec.Mun } & & $-1,96^{\star \star}$ & $-1,87^{\star \star}$ & $-1,59^{\star \star}$ \\
\hline & & $(0,85)$ & $(0,84)$ & $(0,80)$ \\
\hline \multirow[t]{2}{*}{ Frag.Leg.Mun } & & $16,25^{*}$ & $15,51^{*}$ & $18,72^{\star \star}$ \\
\hline & & $(9,60)$ & $(9,56)$ & $(9,19)$ \\
\hline \multirow[t]{2}{*}{ Part.Pop } & & 0,11 & 0,11 & 0,09 \\
\hline & & $(0,11)$ & $(0,11)$ & $(0,11)$ \\
\hline \multirow[t]{2}{*}{ Sexo } & & & 1,12 & 1,56 \\
\hline & & & $(3,50)$ & $(3,37)$ \\
\hline \multirow[t]{2}{*}{ Idade } & & & $0,10^{\star * *}$ & $-0,26^{\star \star *}$ \\
\hline & & & $(0,105)$ & $(0,09)$ \\
\hline \multirow[t]{2}{*}{ Escolaridade } & & & $2,20^{\star \star *}$ & $2,07^{\star \star \star}$ \\
\hline & & & $(0,64)$ & $(0,64)$ \\
\hline \multirow[t]{2}{*}{ Receita } & & & & 4,06 \\
\hline & & & & $(4,74)$ \\
\hline \multirow[t]{2}{*}{ Pessoal } & & & & $-15,28^{\star \star \star}$ \\
\hline & & & & $(4,36)$ \\
\hline \multirow[t]{2}{*}{ Investimento } & & & & $48,65^{\star \star \star}$ \\
\hline & & & & 22,73) \\
\hline
\end{tabular}


Tabela 3 - Regressão para o modelo de painel com efeitos fixos e erros-padrão robustos. Variável dependente: Montante de recursos recebidos por município por ano per capita (Continuação)

\begin{tabular}{|c|c|c|c|c|}
\hline \multirow[t]{2}{*}{ Trans.Obrig } & & & & $172,38^{\star \star \star}$ \\
\hline & & & & $(35,30)$ \\
\hline \multirow[t]{2}{*}{ Restos } & & & & 29,08 \\
\hline & & & & $21,21)$ \\
\hline \multirow[t]{2}{*}{ Expec.Vida } & & & & $-1,64^{\star *}$ \\
\hline & & & & $(0,80)$ \\
\hline \multirow[t]{2}{*}{ Analfabetismo } & & & & 0,87 \\
\hline & & & & $(0,65)$ \\
\hline Número de observações & 66.329 & 53.153 & 53.152 & 50.905 \\
\hline Número de municípios & 5.558 & 5.445 & 5.444 & 5.432 \\
\hline R-quadrado (within) & 0,112 & 0,116 & 0,117 & 0,133 \\
\hline
\end{tabular}

Fonte: Elaborado pelos autores.

Nota: Erro padrão em parênteses. ${ }^{* *} \mathrm{p}<0,01,{ }^{* *} \mathrm{p}<0 ., 5,{ }^{*} \mathrm{p}<0,1$

Nota: Todas as regressões incluíram dummies de ano e dummies de estado-ano.

De acordo com os resultados descritos na Tabela 3, o efeito da identidade partidária entre o Poder Legislativo Federal e o Poder Executivo Municipal no montante total conveniado per capita aponta que os municípios que possuem essa identidade recebem transferências voluntárias superiores em média, há um aumento de $\mathrm{R} \$ 3,24$ por habitante (Modelo 4). Esta é uma contribuição original da presente pesquisa que reforça a tese de que os partidos políticos desempenham importante papel no direcionamento das transferências voluntárias da União para os municípios. ${ }^{18}$

Esse resultado mostra um importante papel do Legislativo na determinação das políticas públicas subnacionais. No entanto, também foi evidenciado um efeito direto ainda mais forte quando o prefeito é do mesmo partido do presidente, em média, $\mathrm{R} \$ 7,43$ por habitante. Este resultado sugere que, ainda que tenhamos identificado o papel significativo do Legislativo no direcionamento dos convênios com os municípios, o Executivo nacional ainda exerce papel prevalente sobre esse direcionamento. Portanto, os resultados aqui obtidos corroboram os estudos de Ferreira e Bugarin $(2004,2007)$, os quais sugerem que as transferências voluntárias intergo-

${ }^{18}$ Registre-se limitação deste estudo quanto ao risco de possível causalidade reversa, dado que os prefeitos também são importantes para as eleições dos deputados federais. Metodologias alternativas, como possivelmente experimentos ou regressão descontínua poderiam ajudar a suprir essa limitação. Agradecemos a um parecerista anônimo pelo comentário. 
venamentais no Brasil são significativamente influenciadas por motivações político-partidárias entre os respectivos poderes executivos. $\mathrm{O}$ resultado também está em linha com a teoria da preponderância do Executivo sobre o Legislativo no país, avançada em Pereira \& Mueller (2004).

Ademais, o estudo evidencia um menor nível de transferência quando o prefeito e o governador pertencem ao mesmo partido, praticamente anulando a vantagem de o prefeito pertencer ao mesmo partido do presidente. Esse resultado parece associado ao fenômeno denominado de "strategic partisan transfer" em Bugarin e Marciniuk (2017), também encontrado para os Estados Unidos em Garofalo (2019), segundo o qual o Executivo federal apenas transferiria mais recursos aos prefeitos de municípios de mesmo partido quando esses municípios estivessem em estados cujos governadores pertenceriam a partidos distintos.

Prefeitos de primeiro mandato e candidatos à reeleição (Gl) apresentam maior recebimento de transferências voluntárias em média ( $\$$ \$8,03 por habitante) em relação a outros possíveis casos. Em oposição, os prefeitos de primeiro mandato e que não são candidatos à reeleição recebem em média menos transferências voluntárias. Esse resultado se relaciona com a pesquisa apresentada em Marciniuk e Bugarin (2019) e sugere um menor esforço no sentido de conseguir recursos adicionais da União quando o prefeito não vê perspectiva de reeleição.

Outro resultado relevante está associado à variável ideologia, em que, quanto mais à direita se encontra a posição ideológica do partido que governa o município, menores valores em média são recebidos via transferências voluntárias. Além de corroborar alguns estudos que relacionam gastos públicos elevados a partidos de esquerda enquanto os de direita seriam mais propensos à disciplina fiscal (Tavares 2004), esse resultado pode ser parcialmente consequência do fato de que em grande parte do período considerado, o presidente da república pertencia a um partido de esquerda. ${ }^{19}$

Os resultados também sugerem que quanto maior a competitividade nas eleições para prefeitos (Comp.Exec.Mun), menores são as transferências voluntárias. Essa relação entre os altos níveis de competitividade e a influência negativa nas transferências voluntárias pode ser explicada à luz do

${ }^{19}$ Bugarin e Marciniuk (2017) também encontram um viés pró-esquerda nas transferências no período em que o PT esteve no governo e, além disso, encontram um viés pró-direita no período em que o PSDB esteve no governo. 
modelo dos core-voters (Cox e McCubbins 1986), indicando que a melhor estratégia para os partidos, na tentativa de maximizar votos, tenderia ser aplicar seus recursos em seus eleitores fiéis e apoiadores (core-voters) em vez de aplicar no eleitor indeciso (swing voter).

Os demais resultados interessantes relacionados, por exemplo, ao papel da idade e da escolaridade do prefeito ou ainda das finanças públicas municipais são deixadas para avaliação do leitor interessado.

De forma a testar a robustez do resultado encontrado foi ainda desenvolvido um estudo econométrico alternativo em que a variável dependente passou a ser o montante de recursos recebidos pelo município, mas agora dividido não pela população, mas pela receita corrente líquida municipal. Ademais, os dados foram desagregados de acordo com os principais ministérios dos quais se originaram as transferências. Os resultados obtidos reforçam aqueles encontrados na análise das transferências per capita, corroborando a robustez do achado. ${ }^{20}$

\section{Conclusão}

Este artigo caracterizou a concentração dos votos dos partidos políticos para as eleições do Legislativo Federal por meio do índice de quociente locacional (QL). A partir do cálculo do indicador QL, construiu-se uma variável de identidade partidária entre o Poder Legislativo Federal e o Poder Executivo Municipal, a qual é a principal variável de interesse nos testes empíricos.

O principal resultado e, também, a contribuição original da pesquisa, é a evidência empírica de que as transferências voluntárias são fortemente direcionadas aos municípios que possuem identidade partidária com os partidos com influência política na região. Os resultados reforçam a tese de que os partidos políticos desempenham um importante papel no direcionamento dessas transferências e, além disso, evidenciam o poder conferido aos parlamentares na determinação das políticas públicas subnacionais. ${ }^{20}$ Por economia de espaço, os detalhes dessas regressões não foram incluídos neste artigo, mas
encontram-se disponíveis sob demanda aos autores. 
No entanto, ainda que tenhamos identificado o papel significativo do Legislativo no direcionamento dos convênios com os municípios, notou-se que o Executivo nacional ainda exerce papel prevalente sobre esse direcionamento.

Outro resultado importante sugere que prefeitos de primeiro mandato e com perspectivas de reeleição tendem a receber maiores aportes de convênios públicos ao compararmos com prefeitos de primeiro mandato sem essa perspectiva e com prefeitos de segundo mandato, o que sugere um menor esforço no sentido de conseguir recursos adicionais da União quando o prefeito não vê perspectiva de reeleição. A relação entre possibilidade e perspectiva de reeleição do prefeito e comportamento fiscal dos municípios é cuidadosamente estudada em Marciniuk e Bugarin (2019).

Enfim, os testes estatísticos apresentados podem contribuir para um melhor entendimento da execução das transferências voluntárias no Brasil, consideradas como recursos clientelistas e distributivos, muitas vezes com impactos negativos política e economicamente.

O presente artigo constitui uma tentativa de melhor evidenciar e entender o efeito da identidade partidária entre o Poder Legislativo federal e o Poder Executivo local nas transferências de rendas voluntárias da União para os municípios, aspecto de grande importância diante das alterações normativas recentes que estabeleceram o "orçamento impositivo" para parte das emendas parlamentares e de bancada à LOA.

O estudo poderia ser ampliado em diversos aspectos para aprofundar a compreensão dos contornos políticos na distribuição desse tipo de recurso. Inicialmente poder-se-ia analisar separadamente as transferências voluntárias efetivamente emendadas pelos parlamentares e, dessa forma, tentar entender o efeito da identidade partidária com os parlamentares que possuem poder político na região de forma individual. Em segundo lugar, poder-se-ia incluir variáveis para os senadores federais e, além disso, incluir no estudo as transferências voluntárias de origem estadual para os municípios. Ademais, pode ser feito de forma cuidadosa o teste da "Strategic Partisan Transfers Hypothesis" (Bugarin e Marciniuk 2017; Garofalo 2019), segundo o qual as transferências diretas do governo federal aos municípios não sofre incremento político quando as três esferas de governo (nacional, estadual e municipal) encontram-se dirigidas pelo mesmo partido; a ideia é que, nesse caso, o governo federal focaria suas transferências políticas no 
governo estadual que, sendo de confiança, por sua vez faria a melhor distribuição para seus municípios. Para esse teste, seria fundamental adicionar ao banco de dados informações complementares sobre as transferências da União aos Estados. Finalmente, o resultado aqui obtido poderia ser testado com a metodologia de RDD como em Brollo e Nannicini (2012), Firpo et al. (2015) e Schneider et al. (2020). Essas extensões são deixadas como sugestões para pesquisas futuras.

\section{Referências}

Ansolabehere, Stephen, e James M. Snyder Jr. "Party control of state government and the distribution of public expenditures." Scandinavian Journal of Economics 108, no. 4 (2006): 547-569.

Ames, Barry. "Electoral rules, constituency pressures, and pork barrel: bases of voting in the Brazilian Congress.” The Journal of Politics 57, no. 2 (1995a): 324-343.

Ames, Barry. "Electoral strategy under open-list proportional representation." American Journal of Political Science (1995b): 406-433.

Ames, Barry. Entraves da Democracia no Brasil. Rio de Janeiro: Fundação Getulio Vargas Editora, 2003. de Holanda Barbosa, Fernando, Ana L. N. de Holanda Barbosa, Carlos E. G. Cavalcanti, Carlos R. L. da Silva, João R. Motta, e Maria L. de M. Roarelli. Federalismo fiscal, eficiência e equidade: uma proposta de reforma tributária. Rio de Janeiro: Fundação Getulio Vargas Editora, 1998. Disponível em: http://www. fgv.br/professor/epge/fholanda/Arquivo/Fede ralismoFiscal.pdf acesso em 4/7/2019.

Bendavid-Val, Avrom. Regional and Local Economic Analysis for Practioners. New York: Praeger, 1991.

Brasil. Constituição da República Federativa do Brasil. Brasília, DF: Brasília: Centro Gráfico do Senado Federal, 1988.

Brollo, Fernanda, e Tommaso Nannicini. "Tying your enemy's hands in close races: the politics of federal transfers in Brazil.” American Political Science Review 106, no. 4 (2012): 742-761.

Bugarin, Mauricio S., Mirta N. S. Bugarin, e Henrique A. Pires. "Deficit targeting: An incentive mechanism for subnational fiscal deficit reduction in Brazil." em Economic Development in Latin America, eds. Hadi S. Esfahani (et al.). London: Palgrave Macmillan, 2010. 254-272.

Bugarin, Maurício, e Sérgio R. B. Gadelha. "Descentralização administrativa e de receitas” em Reforma do Estado - Transformando a atuação do Governo, eds. Fábio Giambiagi, Sérgio G. Ferreira, e Antônio M. H. Ambrózio. GEN Editorial, 2020 (no prelo).

Bugarin, Mauricio, and Fernanda Marciniuk. "Strategic partisan transfers in a fiscal federation: Evidence from a new Brazilian database.” Journal of Applied Economics 20, no. 2 (2017): 21 1-239.

Cardoso, Fernando H., e Ricardo A. Setti. A arte da política: a história que vivi. Rio de Janeiro: Civilização Brasileira, 2006.

de Carvalho, Nelson R. "Geografia política das eleições congressuais: a dinâmica de representação das áreas urbanas e metropolitanas no Brasil.” Cadernos Metrópole 11, no. 22 (2009): 367-384.

Cox, Gary W., e Mathew D. McCubbins. "Electoral politics as a redistributive game." The Journal of Politics 48, no.2 (1986): 370-389. 
Dollery, Brian E., e Keiichi Yamazaki. "Is bigger really better? A comparative analysis of municipal mergers in Australian and Japanese local government." International Journal of Public Administration 41, no. 9 (2018): 725-734.

Ferreira, Ivan FS, e Mauricio S. Bugarin. "Transferências voluntárias e ciclo político-orçamentário no federalismo fiscal brasileiro." Revista Brasileira de Economia 61, no. 3 (2007): 271-300.

Ferreira, Ivan F. S., e Mauricio S. Bugarin. "Transferências Voluntárias no Federalismo Fiscal Brasileiro: efeito do ciclo fiscal de meio de mandato sobre as eleições municipais." em Finanças Públicas: IX Prêmio Tesouro Nacional 9. Brasília: ESAF, 2004: 221-278.

Figueiredo, Argelina C., e Fernando Limongi. "Incentivos Eleitorais, Partidos e Política Orçamentária." Dados 45, no. 2. (2002): 0011-5258.

Figueiredo, Argelina Maria Cheibub. Política orçamentária no presidencialismo de coalizão. Rio de Janeiro: Konrad Adenauer FGV Editora, 2008.

Firpo, Sergio, Vladimir Ponczek, e Viviane Sanfelice. "The relationship between federal budget amendments and local electoral power." Journal of Development Economics 116 (2015): 186-198.

Garofalo, Pablo J. "Strategic spending in federal governments: theory and evidence from the US." Journal of Applied Economics 22, no.1 (2019): 243-272.

Golden, Miriam A., and Lucio Picci. "Pork-barrel politics in postwar Italy, 1953-94." American Journal of Political Science 52, no.2 (2008): 268-289.

Gonschorek, Gerrit J., Günther G. Schulze, e Bambang S. Sjahrir. "To the ones in need or the ones you need? The political economy of central discretionary grants- empirical evidence from Indonesia." European Journal of Political Economy 54 (2018): 240-260.

Lopez, Felix, Mauricio Bugarin, e Karina Bugarin. "Mudanças político-partidárias e rotatividade dos cargos de confiança (1999-2013)." Em Cargos de Confiança e o Presidencialismo de Coalizão no Brasil. Ed. Felix Lopez. Brasília: IPEA (2015): 33-70.

Mainwaring, Scott. "Politicians, parties, and electoral systems: Brazil in comparative perspective." Comparative Politics 24, no.1 (1991): 21-43.

Marciniuk, Fernanda L., e Maurício S. Bugarin. "A influência da reeleição nas políticas fiscais subnacionais." Revista Brasileira de Economia 73, no.2 (2019): 181-210.

Mayhew, David R. Congress: The electoral connection. Vol. 26. Yale University Press, 1974.

Mendes, Marcos, Rogério B. Miranda, e Fernando A. B. Cossío. Transferências intergovernamentais no Brasil: diagnóstico e proposta de reforma. Textos para discussão n. 40. Brasília: Consultoria Legislativa do Senado Federal, 2008.

Nicolau, Jairo. "O sistema eleitoral de lista aberta no Brasil.” Dados 49, no.4 (2006): 689-720.

Pereira, Carlos, e Bernardo Mueller. "Comportamento estratégico em presidencialismode coalizão: as relações entre Executivo e Legislativo na elaboração do orçamento brasileiro.” Dados 45, no.2 (2002): 265-301.

Pereira, Carlos, e Bernardo Mueller. "Partidos fracos na arena eleitoral e partidos fortes na arena legislativa: a conexão eleitoral no Brasil." Dados 46, no.4 (2003): 735-771.

Pereira, Carlos, e Bernardo Mueller. "A theory of executive dominance of congressional politics: the committee system in the Brazilian chamber of deputies." The Journal of Legislative Studies 10, no.1 (2004): 9-49.

Pereira, Carlos, e Lucio Rennó. "O que é que o reeleito tem? Dinâmicas político-institucionais locais e cionais nas eleições de 1998 para a Câmara dos Deputados.” Dados 44, no.2 (2001): 133-172.

Porto, Alberto, e Pablo Sanguinetti. "Political determinants of intergovernmental grants: Evidence from Argentina." Economics \& Politics 13, no.3 (2001): 237-256.

Rae, Douglas W., and Michael Taylor. The analysis of political cleavages. Yale University Press, 1970. 
Rozevitch, Shimon, e Avi Weiss. "Beneficiaries from federal transfers to municipalities: The case of Israel." Public Choice 76, no.4 (1993): 335-346.

Sakurai, Sergio N., e Maria I. A. Theodoro. "On the relationship between political alignment and government transfers: triple differences evidence from a developing country." Empirical Economics 5, no.3 (2020): 1107-1141.

Schneider, Rodrigo, Diloá Athias, e Mauricio Bugarin. "Electronic voting and public spending: the impact of de facto enfranchisement on federal budget amendments in Brazil." Journal of Applied Economics 23, no.1 (2020): 299-315.

Silva, Glauco P. Verificação Empírica sobre o Conceito de Dominância Política: o caso Paulista. In: 7o Encontro da ABCP, Recife, 2010.

Silva, Glauco Peres da. "Uma avaliação empírica da competição eleitoral para a Câmara Federal no Brasil." Opinião Pública 19, no.2 (2013): 403-429.

Silva, Glauco P. da, Ciro Biderman, e George Avelino Filho. "Indicadores para avaliar o comportamento parlamentar como resultante de eleições." In: 33 Encontro Anual da Anpocs, Caxambu, (2009).

Silva, Glauco P. da, e Andreza Davidian. "Identification of areas of vote concentration: evidences from Brazil." Brazilian Political Science Review 7, n.2 (2013): 141-155.

Sodré, Antonio Carlos de Azevedo, and Maria Fernanda Colaço Alves. "Relação entre emendas parlamentares e corrupção municipal no Brasil: estudo dos relatórios do programa de fiscalização da Controladoria-Geral da União." Revista de Administração Contemporânea 14, no.3 (2010): 414-433.

Solé-Ollé, Albert, e Pilar Sorribas-Navarro. "The effects of partisan alignment on the allocation of intergovernmental transfers. Differences-in-differences estimates for Spain." Journal of Public Economics 92, no.12 (2008): 2302-2319.

Stein, Robert M., e Kenneth N. Bickers. "Congressional elections and the pork barrel." The Journal of Politics 56, no.2 (1994): 377-399.

Taagepera, Rein. "Inequality, concentration, imbalance." Political Methodology (1979): 275-291.

Tamura, Kenichi. Testing the Partisan Bias in the Japanese Fiscal Equalization System. Paper presented at the GLOPE II International Symposium, POLITICAL ECONOMY of INSTITUTIONS and EXPECTATIONS II, Tokyo: Waseda University, December 18-19, 2010. Disponível em http://www.waseda.jp/ fpse/gcoe/sympo/20101218/paper/Tamura.pdf, acesso em 27/6/2019.

Tavares, José. "Does right or left matter? Cabinets, credibility and fiscal adjustments." Journal of Public Economics 88, no.12 (2004): 2447-2468.

Teixeira, Luciana, Maria Cristina MacDowell, e Maurício Bugarin. "Incentivos em consórcios intermunicipais de saúde: uma abordagem de teoria dos contratos." Estudos Econômicos (São Paulo) 32, no.3 (2002): 339-365.

Veiga, Linda G., e Maria M. Pinho. "The political economy of intergovernmental grants: Evidence from a maturing democracy." Public Choice 133, no.3-4 (2007): 457-477.

Veiga, Linda G., e Francisco J. Veiga. "Intergovernmental fiscal transfers as pork barrel." Public choice 155, no.3-4 (2013): 335-353.

Wright, Gavin. "The political economy of New Deal spending: An econometric analysis." The Review of Economics and Statistics (1974): 30-38.

World Economic Outlook. World Economic and Financial Surveys. International Monetary Fun (FMI). Abril 2016.

Zucco Jr., Cesar and Power, Timothy J. "Estimating ideology of Brazilian legislative parties, 1990-2005: a research communication." Latin American Research Review (2009): 218-246.

Zucco Jr., Cesar. The Ideology of Brazilian Parties: technical notes on the third edition of estimates. Mimeo, 10 jan. 2014. 